\title{
Cadmium induces neuronal cell death through reactive oxygen species activated by GADD153
}

\author{
Seungwoo Kim ${ }^{1 \dagger}$, Hyo-Soon Cheon ${ }^{1 \dagger}$, So-Young Kim ${ }^{2}$, Yong-Sung Juhnn ${ }^{2}$ and Young-Youl Kim ${ }^{*}$
}

\begin{abstract}
Background: Cadmium(Cd), a heavy metal, which has a potent harmful effects, is a highly stress-inducible material that is robustly expressed following disruption of homeostasis in the endoplasmic reticulum (ER) (so-called ER stress). The mechanism Cd induced cell death of neuroblastoma cells complex, involving cellular signaling pathways as yet incompletely defined but, in part, involving the generation of reactive oxygen species (ROS). Several studies have correlated GADD153 expression with cell death, but a mechanistic link between GADD153 and apoptosis has never been demonstrated.

Results: SH-SY5Y cells were treated Cd led to increase in intracellular ROS levels. ROS generation is not consistent with intracellular $\left[\mathrm{Ca}^{2+}\right]$. The exposure of neuroblastoma cells to $\mathrm{Cd}$ led to increase in intracellular GADD153 and Bak levels in a doses and time dependent manner. The induction of these genes by $\mathrm{Cd}$ was attenuated by NAC. Cd-induced apoptosis is decreased in GADD153 knockdown cells compared with normal cells. The effect of GADD153 on the binding of C/EBP to the Bak promoters were analyzed ChIP assay. Basal constitutive GADD153 recruitment to the $-3,398 /-3,380$ region of the Bak promoter is observed in SH-SY5Y cells.

Conclusions: The exposure of SH-SY5Y cells to Cd led to increase in intracellular ROS levels in a doses and time dependent manner. The generation of ROS result in the induction of GADD153 is causative of cadmium-induced apoptosis. GADD153 regulates Bak expression by its binding to promoter region (between $-3,398$ and $-3,380$ ). Therefore, we conclude that GADD153 sensitizes cells to ROS through mechanisms that involve up-regulation of BAK and enhanced oxidant injury.
\end{abstract}

Keywords: Cadmium, ROS, ER, Bak

\section{Background}

ROS are constantly generated under normal conditions as a consequence of aerobic metabolism, and the most common ROS types are superoxide anions (O2-), hydrogen peroxide $\left(\mathrm{H}_{2} \mathrm{O}_{2}\right)$ and hydroxyl radicals (HO-) [1]. ROS can react with DNA, proteins, carbohydrates, and lipids in a destructive manner due to their high levels of chemical reactivity. ROS participate in the modulation of apoptosis following treatment with various agents including Fas, ultraviolet, and chemotherapeutic drugs [2]. Several previous studies also indicated involvement of ROS in cadmium-induced renal tubular injury. For

\footnotetext{
*Correspondence: youngyk@gmail.com

${ }^{\dagger}$ Equal contributors

${ }^{1}$ Center for Biomedical Science, Division of Brain Diseases, National Institute of Health in Korea (KNIH), Osong Health Technology Administration Complex, 187 songsaengmyeong2(i)-ro, Gangoe-myeon, Cheongwon-gun, Chungcheongbuk-do 363-951, Korea

Full list of author information is available at the end of the article
}

example, exposure of LLC-PK1 cells to cadmium caused generation of ROS [3], which was associated with a decrease in glutathione levels and consequent cellular death [4]. Another report showed that Cd-triggered apoptosis of tubular cells is inhibited by an antioxidant [5].

However, currently, it is unknown whether and how oxidative stress is linked to ER stress and, if so, what kind of ROS are involved in the induction of apoptosis in cadmium-exposed cells. GADD153 is a member of the C/EBP family of bZIP transcription factors, and its expression is induced to high levels by ER stress [6]. GADD153 forms hetero-dimers with other C/EBP-family transcription factors via bZIP-domain interactions, which suppresses their binding to C/EBP sites in DNA, while promoting binding to alternative DNA sequences for target gene activation [7]. Consequently, GADD153 inhibits expression of genes responsive to C/EBP-family transcription factors, while enhancing expression of other genes 
containing the consensus motif $5^{\prime}-(\mathrm{A} / \mathrm{G})(\mathrm{A} / \mathrm{G})(\mathrm{A} / \mathrm{G})$ TGCAAT(A/C)CCC-3'. One relevant target may be bcl-2, whose expression is suppressed by GADD153, at least in some cellular contexts [8]. While capable of inducing apoptosis and contributing to cell death in several scenarios involving ER stress, GADD153 is not essential for cell death induced by ER stress, as demonstrated by the observation that perk $^{-/-}$and eIF2 $\alpha(\mathrm{S} 51 \mathrm{~A})$ knock-in cells are hypersensitive to ER stress-induced apoptosis but fail to induce gadd153 gene expression $[9,10]$. Splenic lymphocytes from GADD $153^{-/-}$mice are relatively resistant to LPS-induced apoptosis, which is associated with increased Bax and Bak mRNAs and decreased Bcl-2 mRNA (S Oyadomari et al., unpublished observation). Furthermore, the activation of GADD153 leads to translocation of Bax protein from the cytosol to the mitochondria [8]. Thus, GADD153-mediated death signal is finally transmitted to the mitochondria, which functions as an integrator and amplifier of the death pathway.

Clearly, there is great need for more definitive evidence of the involvement of Gadd153 in apoptosis. In this study, we sought to define in greater detail what role, if any, Gadd153/Bak plays in the regulation of cell death. We report that while Gadd153 expression alone does not trigger cell death, it does sensitize cells to killing by agents that stress the ER. Furthermore, we demonstrate that elevated Gadd153 expression up-regulates expression of Bak and the primary intracellular scavenger of ROS.

\section{Results}

\section{Cd induces apoptosis of neuronal cells through ROS}

$\mathrm{Cd}$ induces the production of ROS [11] and ER stress, which are importa nt triggers of the stress response in many cell types $[12,13]$. Previous report indicated involvement of ROS in Cd-induced renal cell injury [14]. To examine whether $\mathrm{Cd}$ trigger ROS in neuroblastoma cells, we investigated effects of $\mathrm{Cd}$ on the generation of endogenous ROS. Exposure of SH-SY5Y cells to Cd led to both 1.5 to 2 fold increase in intracellular ROS levels in a doses and time dependent manner (Figure 1A, B). To examine whether the generation of ROS is causative of $\mathrm{Cd}$-induced apoptosis, cells were pretreated with antioxidant $\mathrm{N}$-acetylcysteine(NAC) and subjected to fluorescent microscopy and DAPI staining (Figure 1C).

Increased cytoplasmic calcium $\left[\mathrm{Ca}^{2+}\right]$ resulted either from calcium $\left(\mathrm{Ca}^{2+}\right)$ influx from the extracellular environment or efflux from intracellular ER stores is associated with the initiation of apoptosis in diverse in vivo and in vitro systems [15]. To investigate the role of intracellular $\left[\mathrm{Ca}^{2+}\right]$ in $\mathrm{Cd}$-induced ROS generation, cells were pretreated for $12 \mathrm{hr}$ with the $\mathrm{Ca}^{2+}$ chelator BAPTA-AM $(10 \mu \mathrm{M})$ before treatment with $25 \mu \mathrm{M} \mathrm{Cd}$ treatment, Cd-induced ROS level is not changed (Figure 1D). In addition, BAPTA-AM is not effective in Cd-induced apop- tosis (Figure 1E). This indicates that ROS generation is not consistent with intracellular $\left[\mathrm{Ca}^{2+}\right]$.

\section{Cd increases GADD153 and Bak expression via ROS}

$\mathrm{Cd}$ induced apoptosis of SH-SY5Y cell is mediated, at least in part, by ER stress $[16,17]$. Dose dependent experiment revealed that induction of GADD153 was observed from $25 \mathrm{uM}$ to $50 \mathrm{uM} \mathrm{Cd}$ treatment (Figure 2A). The activation of GADD153 leads to translocation of this transcription factor from the cytosol to the nucleus. Therefore, we examined the level of GADD153 after Cd treatment in nuclear extract. As shown Figure 2B, the level of GADD153 in nuclear extract is increased by $\mathrm{Cd}$. To investigate relationship between oxidative stress and ER stress, SH-SY5Y cells were treated with $\mathrm{Cd}$ in the absence or presence of NAC, and expression of endogenous ER stress marker GADD153 was examined. Western blot analysis revealed that induction of GADD153 by Cd is completely attenuated by NAC (Figure $2 \mathrm{C}$ ).

The cDNA array screen also identified the proapoptotic BCL2 family protein BAK as a fenretinideinducible gene in SH-SY5Y cells, and this is confirmed by immunofluorescence flow cytometry and western blot data [18]. Studies on other cell types have shows that BAK can induce the release of cytochrome c from mitochondria, independently of mitochondria permeability transition, in combination with BH3 domain-only members of the BL2 family [19]. Therefore, the induction of BAK may be an event downstream of GADD153 induction leading to cytochrome c release and subsequent apoptosis in $\mathrm{Cd}$ treated neuroblastoma cells.

To exclude a possibility that GADD153 is not located downstream of Bak, SH-SY5Y cells were treated with $\mathrm{Cd}$ in the absence or presence of NAC and expression of endogenous Bak was examined. Western blot analysis revealed that induction of Bak by $\mathrm{Cd}$ was partially attenuated by NAC (Figure 2C). Exposure of SH-SY5Y cells to $\mathrm{Cd}$ led to increase in intracellular Bax levels in a doses dependent manner (Figure 2C). These findings indicate that the GADD/Bak pathway plays a apoptosis role in Cd-induced cell death in SH-SY5Y cells.

\section{Knockdown of GADD153 downregulates Cd-induced apoptosis via Bak}

Several studies have proposed that GADD153 activation results is apoptosis [20-22]. To investigate the role of GADD153 in Cd-induced apoptosis in SH-SY5Y cells, cells were transfected with small interfering RNA (siRNA) targeted against the GADD153 coding region and then treated with $\mathrm{Cd}$ (Figure 3A). As demonstrated in the literature, activation of Bak by $\mathrm{Cd}$ is decreased by knockdown of GADD153 (Figure 3B). Cd-induced apoptosis is decreased in GADD153 knockdown cells compared with control cell (Figure 3C). 
B
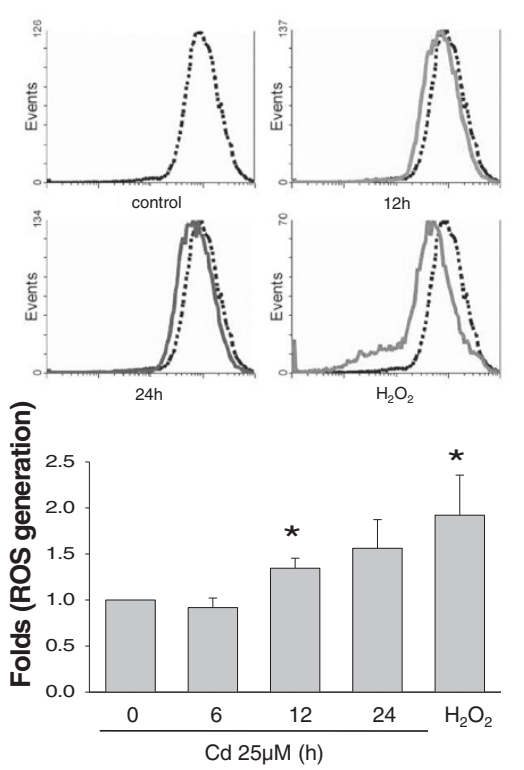

C
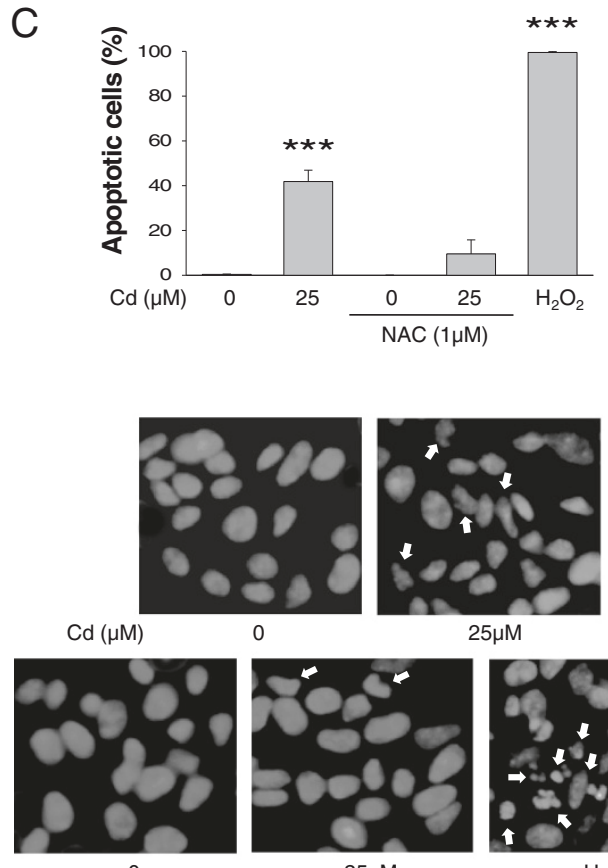

$25 \mu \mathrm{M}$

NAC $(1 \mu \mathrm{M})$

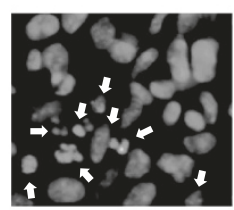

$\mathrm{H}_{2} \mathrm{O}_{2}$

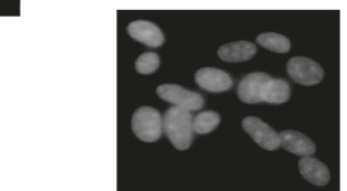

$\mathrm{Cd}(\mu \mathrm{M})$

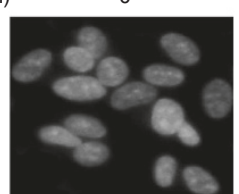

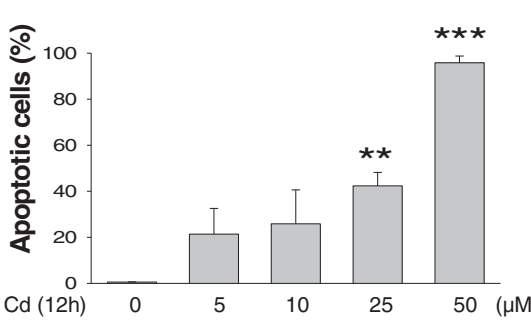

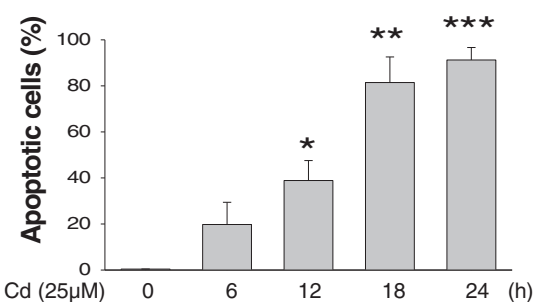

D

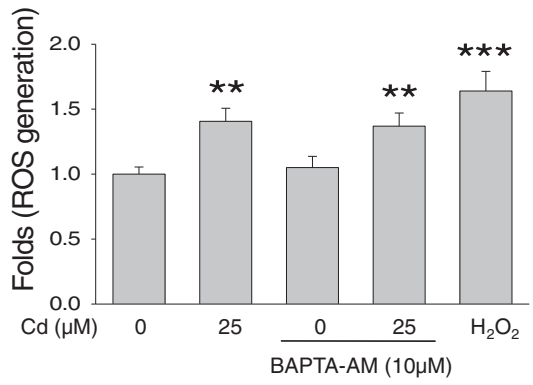

$E$
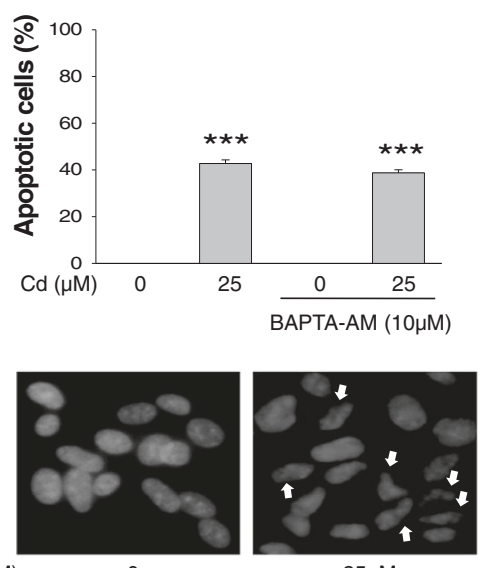

$25 \mu \mathrm{M}$

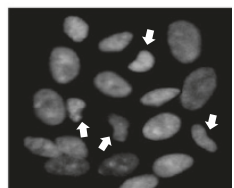

$25 \mu \mathrm{M}$

Figure 1 (See legend on next page.) 

solid line) (upper panel). ROS-generation was measured using $\mathrm{H}_{2} \mathrm{DCFDA}$ as described in the materials and method and quantified (lower panel).

(A). $\mathrm{CdCl}_{2}$-induced apoptosis measured by annexin $\mathrm{V}$ binding for various dose (upper panel) and time (lower panel) of $\mathrm{CdCl}_{2}$. Apoptotic cells were quantified. (B). SH-SY5Y cells were treated with or without a ROS scavenger, NAC $(1 \mu \mathrm{M})$ for $1 \mathrm{hr}$ and then incubated with $\mathrm{CdCl}_{2}(25 \mu \mathrm{M})$ or $\mathrm{H}_{2} \mathrm{O}_{2}$ for $12 \mathrm{hr}$. Apoptosis was measured by annexin V binding (upper panel) and DAPI staining (lower panel) (C). Annexin V binding apoptotic cells were quantified. Arrows indicated DAPI-positive cells shown fragmentation or nuclei condensation were observed in $\mathrm{CdCl}_{2}$ treated cells. SH-SY5Y cells were pretreated with a calcium chelater, BAPTA-AM $(10 \mu \mathrm{M})$ for $30 \mathrm{~min}$ and then incubated with $\mathrm{CdCl}_{2}(25 \mu \mathrm{M}, 12 \mathrm{hr})$. ROS-generation was quantified (D) and apoptosis was measured by DAPI staining $(\mathbf{E})$. Data are presented as mean \pm SEM, from at least three independent experiments. ${ }^{*} p<0.05,{ }^{* *} p<0.01$ or ${ }^{* * *} p<0.001$ vs. control.

\section{Chromatin immunoprecipitation reveals GADD153 binding to the Bak promoter}

To examine whether GADD153 increases Bak mRNA expression at the transcriptional level, we performed luciferase reporter gene assay. To localize the region of the Bak promoter responsible for GADD153 induction, the effects of serial deletion on Bak luciferase activity were analyzed in SH-SY5Y cells. Treatment with $\mathrm{Cd}$ and GADD153 Bak luciferase activity $3.2 \pm 0.8$ fold under the control of the $-3,500$ bp region versus the vector-transfected control, indicating that inductionfold decreased in the rest of untranslated region of Bak promoter (Figure 4A, B).

To study the mechanism of GADD153 to activate Cdinduced Bak transcription mediated transcription factors, the effect of GADD153 on the binding of C/EBP to the Bak promoters were analyzed ChIP assay in SH-SY5Y cells. As shown Figure 4C, basal constitutive GADD153 recruitment to the $-3,398 /-3,380$ region of the Bak promoter was observed in SH-SY5Y cells.

\section{Discussion}

ROS is implicated in heavy metal-induced apoptosis. The present study was performed to elucidate roles of ROS and downstream events induced-triggered apoptosis. Our results represented that Cd caused ER stress via generation of ROS and ER stress-induced apoptosis via activation of the GADD153/Bak pathway. The outline of our current hypothesis is summarized and illustrated in Figure 4D.

Previous reports indicated that $\mathrm{Cd}$ may induce apoptosis through altered activity of protein kinases, phosphatase and transcription factors, generation of ROS, induction of mitochondrial pathways or activation of caspases [23-25]. Mechanisms involved may be different from cell type to cell type, but among those, mitochondria have been regarded as the crucial target of $\mathrm{Cd}$.

The relationship between oxidative stress and ER stress is not well understood. Haynes et al. reported that prolonged activation of UPR resulted in oxidative stress and consequent cellular death in Saccharomyces cerevisiae. Accumulation of ROS by UPR may be caused through two mechanisms; the oxidative folding machinery in the
ER and the mitochondria dependent ROS generation [26]. However, our current results evidenced that oxidative stress was upstream, but not downstream of ER stress in cadmium-exposed cell. Consistent with our results, some reports also indicated that ER stress may be involved downstream of ROS [12].

GADD153 is a key control point apoptosis in apoptosis of various cell type, and since it is a transcription factor, GADD153 may be responsible for the induction of other genes required for $\mathrm{Cd}$-induced apoptosis in neuroblastoma cells. The necessity for GADD153 in Cd-induced apoptosis has been confirmed by GADD153 si-RNA blocks the apoptotic response to $\mathrm{Cd}$ (Figure 3).

However, GADD153-siRNA doesn't fully prevent Bak expression and apoptosis (Figure 3B). It is suggested that GADD153 activation may not be the sole mechanisms by which $\mathrm{Cd}$ cause cell death. Bax is another regulator in $\mathrm{Cd}$-induced apoptosis (Figure 3C, 4C). Furthermore, level of Bcl-2 (downstream of GADD153-induced apoptosis) is not changed by $\mathrm{Cd}$ (data not shown). Our current finding that $\mathrm{Cd}$-induced cell death raises a possibility that GADD153/Bak may also be involved not only in Cd-induced apoptosis but also in a variety of other biological responses.

The hypothesis that GADD153 is responsible for the induction of Bak was tested by protein-DNA interaction assay. We first hypothesized that putative $\mathrm{C} / \mathrm{EBP}$ binding site may bind GADD153. The binding sites for the transcription factors seems to be localized in the Bak promoter region ( $-3,500 \mathrm{bp})$, because Bak luciferase was found to be increased in proportion to the extent of deletion in this region. The nuclear transcription factor GADD153 may form heterodimers with other C/EBP-family transcription factors and has been linked to a variety of cellular events including proliferation, differentiation and apoptosis [27]. The different members of C/EBP family can forms homodimers, heterodimers with another form of the C/EBPs and with other transcription factors that may or may not contain the leucine zipper domain [28].

We herein show that GADD153 is critical for Cdinduced apoptosis in neuroblastoma cells, Cd-induced Bak expression is mediated through a region between $-3,398$ and $-3,380$ of the Bak promoter. These results 


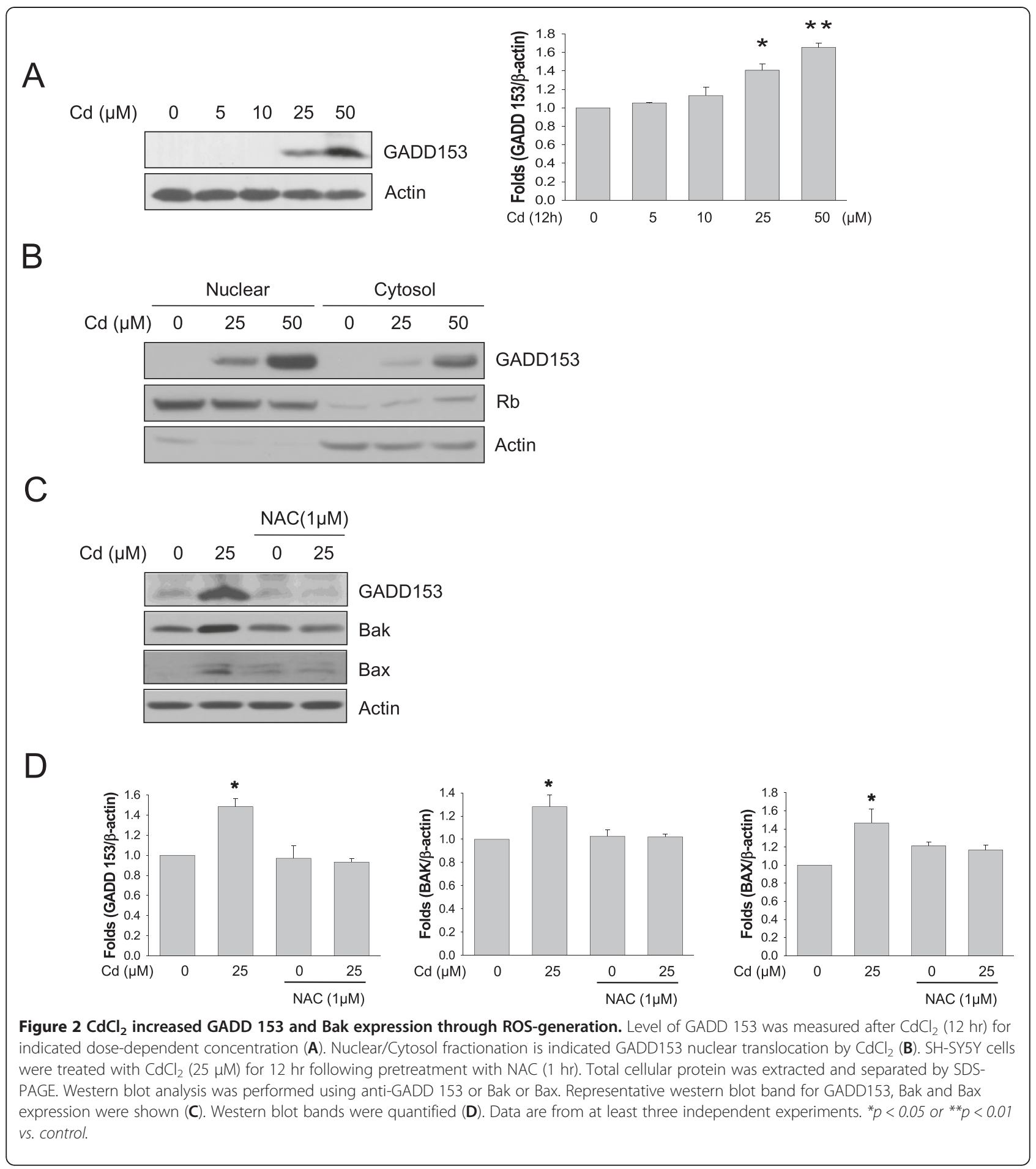

provide evidence for the first time that $\mathrm{Cd}$-induced apoptosis of neuronal cells is mediated, at least in part, by ROS and that regulation via a distinct GADD153/Bak is implicated in the apoptotic process. Further investigation will be required to elucidate the spectrum of pathophysiological significance of the oxidative stress-ER stress axis.

\section{Conclusions}

This study has examined the hypothesis that $\mathrm{Cd}$ induces neuronal cell death through ROS activated by GADD153. Our results are showing exposure of SH-SY5Y cells to Cd led to increase in intracellular ROS levels in a doses and time dependent manner. In addition, the generation of ROS and induction of GADD153 are causative of 


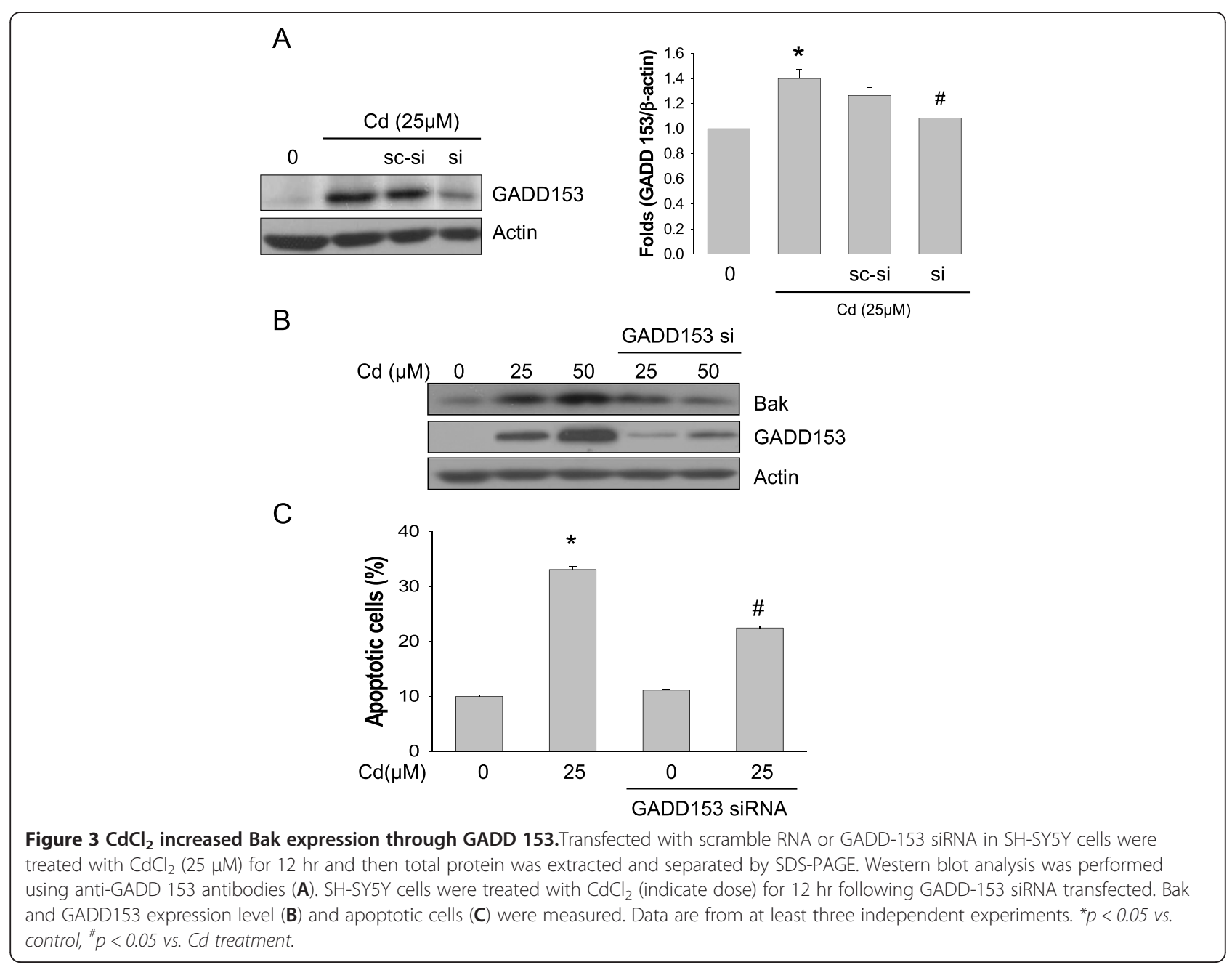

cadmium-induced apoptosis. GADD153 regulates Bak expression by its binding to promoter region (between $-3,398$ and $-3,380)$. These results provide evidence for the first time that $\mathrm{Cd}$-induced apoptosis of neuronal cells is mediated, at least in part, by ROS and that regulation via a distinct GADD153/Bak is implicated in the apoptotic process.

\section{Methods}

\section{Materials}

Dulbecco's modified Eagle's medium (DMEM), fetal bovine serum (FBS) and penicillin/ streptomysin were obtained from Gibco BRL (Gland Island, NY, USA). Cadmium chloride $(\mathrm{Cd})$, NAC (N-acetyl-L-cysteine) were from Sigma (St. Louis, MO, USA). BAPTA-AM [1,2-bis(2aminophenoxy) ethane- $N, N, N, N$ '-tetraacetic acid tetrakis (acetoxy methyl ester)] were obtained from CalbiochemNovabiochem (San Diego, CA, USA). GADD153 antibodies were obtained from abcam (Cambridge, CB4 OFL, $\mathrm{UK}) . \mathrm{Rb}$ and Bax antibodies were obtained from Santa Cruz Biotechnology (Santa cruz, CA, USA). Luciferase assay kit was purchased from Promega (Madison, WI, USA). $2^{\prime}, 7^{\prime}$-dichlorodihydrofluorescein diacetate $\left(2^{\prime}, 7^{\prime}-\right.$ dichlorofluorescein diacetate, $\mathrm{H}_{2}$ DCFDA) were obtained from Molecular Probes (Eugene, OR, USA). pGL2 Bak promoter construct was kindly provided by Dr. Yong-Sung Juhnn(Seoul National University, Korea), pcDNA3GADD153 expression construct was kindly provided by Dr. Dae-Ghon Kim(Chonbuk National University, Korea).

\section{Cell culture}

Human neuroblastoma (SH-SY5Y) cells (ATCC, Rockville, MD, USA) were cultured in DMEM supplemented with $10 \% \mathrm{FBS}, 100$ Units $/ \mathrm{mL}$ penicillin, and $100 \mu \mathrm{g} / \mathrm{mL}$ streptomycin. Cells were maintained in a $37^{\circ} \mathrm{C} / 5 \% \mathrm{CO}_{2}$ incubator.

\section{Measurement of reactive oxygen species}

SH-SY5Y cells were treated with BAPTA-AM for $30 \mathrm{~min}$ and $\mathrm{Cd}$ treated for $11 \mathrm{hr} 30 \mathrm{~min}$. Cells were washed with phosphate-buffered saline (PBS), harvested using trypsin 

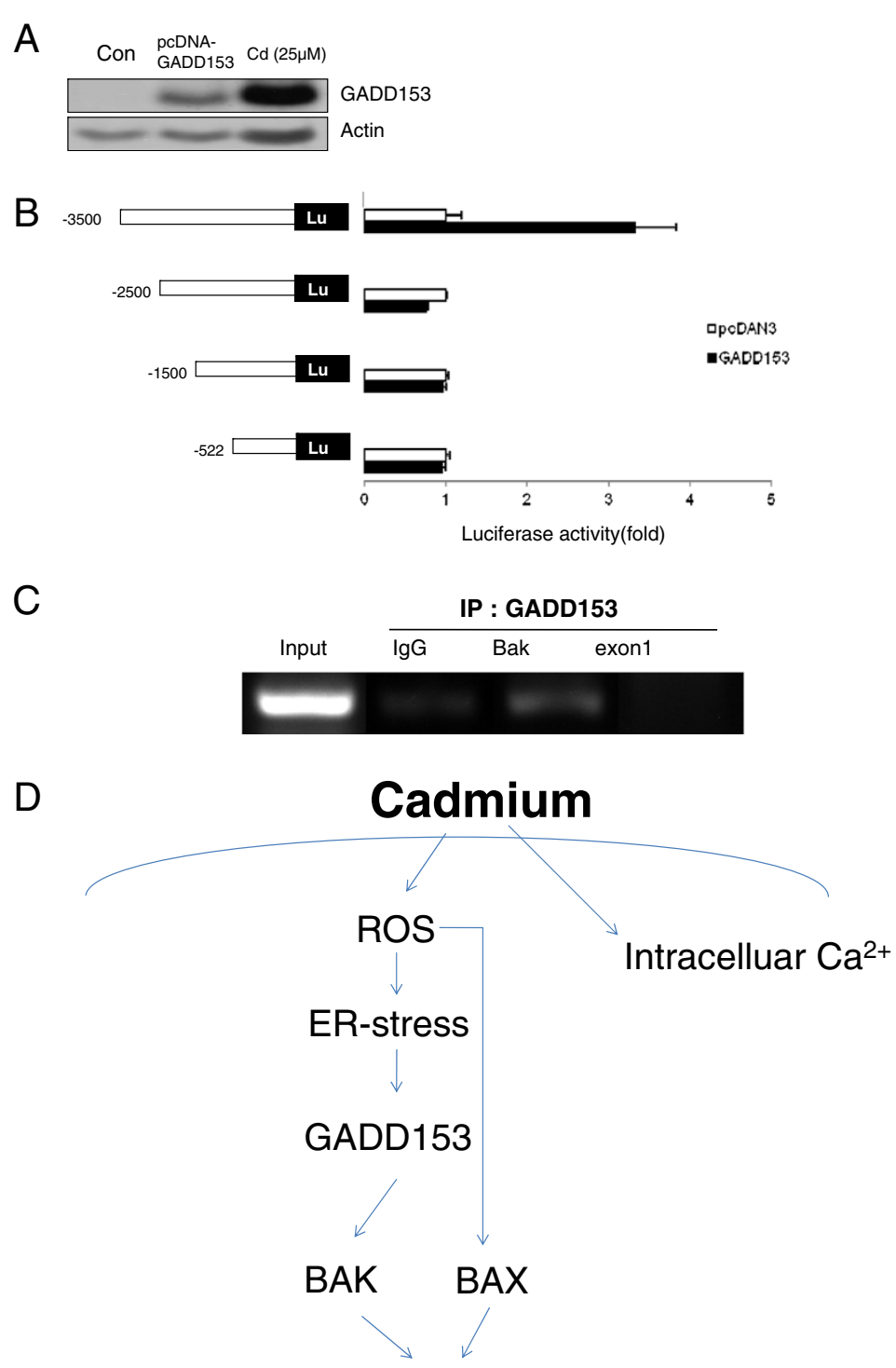

\section{Apoptosis}

Figure 4 GADD153 increased Bak expression level. SH-SY5Y cells transfected with pcDNA3-GADD 153 or treated $\mathrm{CdCl}_{2}(25 \mu \mathrm{M}, 12 \mathrm{hr})$. Total cellular protein was extracted and separated by SDS-PAGE. Western blot analysis was performed using anti-GADD 153 (A). Luciferase activitiy was measured $48 \mathrm{hr}$ after co-transfected PcDNA3-GADD 153 and serial deleted Bak promoter region (B). SH-SY5Y cells were treated with $25 \mu \mathrm{M}$ Cd for $12 \mathrm{~h}$. Cells were cross-linking Histon-DNA complex by adding 37\% formaldehyde for 30 min. Histon-DNA complex sheared between 200 and 1000 bp. ChIP products using specific antibodies directed against pre-immune lgG or GADD 153 were amplified by PCR. Input was sonicated chromatin prior to immunoprecipitation (C). Data are from at least three independent experiments. (D) Scheme of the proposed pathways mediating Cd-induced apoptosis.

and washed with PBS. Resuspend cells in H2DCFDA (final concentration $20 \mu \mathrm{M}$ ) at $37^{\circ} \mathrm{C}$ incubator for $30 \mathrm{~min}$. Cells were washed with PBS and then resuspend in PBS. ROS analyzed by flow cytometry (Beckman culter, Brea, CA, USA).

\section{Measurement of apoptosis by propidium iodide staining} SH-SY5Y cells were treated with Cd for 12 hour that they washed with PBS, harvested using trypsin. Cells were stained with propidium iodide (PI; $5 \mu \mathrm{g} / \mathrm{mL}$ ) in PBS. They were analyzed by flow cytometry, and the extent of apoptosis was determined based on the sub-G1 population.

\section{Transfection and luciferase assay}

SH-SY5Y cells were transfected with plasmid using Lipofectamine 2000 Reagent (Invitrogen, Camarillo, CA, USA) according to the manufacturer's recommendation. Cells 
were incubated for $24 \mathrm{hr}$ in $37^{\circ} \mathrm{C} 5 \% \mathrm{CO}_{2}$ incubator. Luciferase activities were assayed using luciferase assay kit (Promega, Madison, WI, USA), according to the manufacturer's instructions.

\section{Western blot analysis}

Cells were lysed in RIPA buffer [50 mM Tris- $\mathrm{HCl}$, pH 7.5, 1\% NP-40, 0.5\% sodium deoxycholic acid, $0.1 \%$ SDS, and protease inhibitors cocktail (sigma, St. Louis, MO, USA)] on ice for $20 \mathrm{~min}$. Lysates were centrifuged at $12,000 \times g$ for $15 \mathrm{~min}$. Protein $(60 \mu \mathrm{g})$ was separated by $10 \%$ SDS-PAGE, and the proteins were transferred onto a $0.45 \mu \mathrm{m}$ PVDF membrane (Milipore, Bedford, MA, USA). After the membrane was blocked with 5\% fat-free milk in TBST buffer ( $25 \mathrm{mM}$ Tris- $\mathrm{HCl}, \mathrm{pH} 7.4$, $137 \mathrm{mM} \mathrm{NaCl}, 5 \mathrm{mM} \mathrm{KCl}$, and 0.1\% Tween 20) for $3 \mathrm{hr}$, it was incubated with the primary antibodies at $4^{\circ} \mathrm{C}$ overnight and secondary antibodies for $2 \mathrm{hr}$. All antibodies were used at a dilution of 1:1000. Membrane were developed using an enhanced SuperSignal West Femto Chemiluminescent Substrate (Thermo, Waltham, MA, USA).

\section{Nuclear/cytosol fractionation}

Cells were treated with $\mathrm{Cd}$ for 12 hour and then washed two times with PBS, harvested using cell scraper. Cells were centrifuged at $300 \times g$ for $4 \mathrm{~min}$, resuspended buffer A (10 Mm HEPES, pH 7.5, $10 \mathrm{Mm} \mathrm{KCl,} 1 \mathrm{mM}$ DTT, $1 \mathrm{mM}$ PMSF, protease inhibitors cocktail) and incubated for $15 \mathrm{~min}$ on ice. Supernatant (cytosol) was collected by centrifuged at $4^{\circ} \mathrm{C}, 1500 \times \mathrm{g}$ for $5 \mathrm{~min}$ after 10 min incubation on ice with $10 \%$ NP-40. Pellet was washed two times with buffer $\mathrm{A}$ and then resuspended buffer B (buffer $\mathrm{A}+0.4 \mathrm{M} \mathrm{NaCl}$ ) for $30 \mathrm{~min}$ on ice. Supernatant (nuclear) was collected by centrifuged at $4^{\circ} \mathrm{C}, 15000 \times \mathrm{g}$ for $10 \mathrm{~min}$.

\section{DAPI staining \& annexin $V$ assay}

Cells were treated with an NAC for $1 \mathrm{~h}$ and then incubated with $\mathrm{Cd}$ for $12 \mathrm{~h}$. After treatment with $\mathrm{Cd}$, cells were washed with PBS, fixed for 30 min with $4 \%$ paraformaldehyde (PFA) prepared in PBS, followed by incubation with 4',6-diamindine-2-phenilindole (DAPI; $10 \mu \mathrm{g} / \mathrm{mL}$ ) for $30 \mathrm{~min}$. They were analyzed by flow cytometry. Apoptotic cells with condensed or fragmented nuclei were visualized under a fluorescence microscope (Olympus Optical Co., Melville, NY, USA). Apoptotic cells were detected by annexin V assay kit (Molecular Probes, Inc., Eugene, OR, USA), according to the manufacturer's instructions.

\section{ChIP assay}

SH-SY5Y cells were routinely cultured and treated with $25 \mu \mathrm{M} \mathrm{Cd}$ for $12 \mathrm{~h}$. Cells were fixed by adding $37 \%$ formaldehyde (final concentration 1\%) directly to culture medium and incubate for $10 \mathrm{~min}$. Cells were sonicated condition for $15 \mathrm{sec}$ for 18 time, 2 min-intervals, setting $35 \%$ output with micro-tip to keep sample on ice. Cells were detected by Chromatin immunoprecipitation assay kit (Millipore, Temecula, CA, USA), according to the manufacturer's instructions. ChIP products using specific antibodies directed against pre-immune IgG (Santa cruze, Califonia, DA, USA) or GADD153. The purified DNA products were amplified target protein-DNA specific primer (Sense primer: 5'-AATCTAGTATTAGTATTCCCCA-3', Antisense primer: $3^{\prime}$-ACCATTCTGGCTAACATGGTGA-5') and non-specific primer (Sense primer: 5'-GTCTGCAT CCGGTGGCCACA-3', Anti-sense primer: AACCCGGT CCTAGGGCCGTC).

\section{Statistical analysis}

Data are expressed as the mean $\pm \mathrm{SD}$ of experiments performed in triplicate and replicated at least three times. Data were evaluated with one-way analysis of variance (ANOVA) followed by Student's $t$-test. Statistically significant differences are reported as ${ }^{*} \mathrm{p}<0.05$ or ${ }^{*} \mathrm{p}<0.01$. Data with values of $\mathrm{p}<0.05$ were generally accepted as statistically significant.

\section{Competing interests}

The authors declare no competing interests.

\section{Authors' contributions}

The work was carried out in collaboration between all authors. SW and HS carried out most of the experimental work, statistical analysis and wrote drafts of the manuscript. YS and SY carried out construction of Bak promoter vectors. YY supervised most of the experimental work and conceived of the study, participated in the finalized the manuscript. All authors have read and approved the final manuscript.

\section{Acknowledgements}

This study was supported by grants from the Korean National Institute of the Health Intramural Fund (Number 4845-300-210).

\section{Author details}

${ }^{1}$ Center for Biomedical Science, Division of Brain Diseases, National Institute of Health in Korea (KNIH), Osong Health Technology Administration Complex, 187 songsaengmyeong2(i)-ro, Gangoe-myeon, Cheongwon-gun, Chungcheongbuk-do 363-951, Korea. ${ }^{2}$ Department of Biochemistry and Molecular Biology, Cancer Research Institute, Seoul National University College of Medicine, Seoul 110-799, Korea.

Received: 7 August 2012 Accepted: 11 January 2013

Published: 22 January 2013

\section{References}

1. Richter C, Gogvadze V, Laffranchi R, Schlapbach R, Schweizer M, Suter M, Walter $\mathrm{P}$, Yaffee M: Oxidants in mitochondria: from physiology to diseases. Biochim Biophys Acta 1995, 1271:67-74.

2. Suzuki $Y$, Ono $Y$, Hirabayashi $Y$ : Rapid and specific reactive oxygen species generation via NADPH oxidase activation during Fas-mediated apoptosis. FEBS Lett 1998, 425:209-212.

3. Gennari A, Cortese E, Boveri M, Casado J, Prieto P: Sensitive endpoints for evaluating cadmium-induced acute toxicity in LLC-PK1 cells. Toxicology 2003, 183:211-220.

4. Prozialeck WC, Lamar PC: Effects of glutathione depletion on the cytotoxic actions of cadmium in LLC-PK1 cells. Toxicol Appl Pharmacol 1995, 134:285-295. 
5. Thévenod F, Friedmann JM, Katsen AD, Hauser IA: Up-regulation of multidrug resistance $\mathrm{P}$-glycoprotein via nuclear factor-kappaB activation protects kidney proximal tubule cells from cadmium- and reactive oxygen species-induced apoptosis. J Biol Chem 2000, 275:1887-1896.

6. Oyadomari S, Mori M: Roles of CHOP/GADD153 in endoplasmic reticulum stress. Cell Death Differ 2004, 11:381-389.

7. Ubeda M, Wang XZ, Zinszner H, Wu I, Habener JF, Ron D: Stress-induced binding of the transcriptional factor CHOP to a novel DNA control element. Mol Cell Biol 1996, 16:1479-1489.

8. McCullough KD, Martindale JL, Klotz LO, Aw TY, Holbrook NJ: Gadd153 sensitizes cells to endoplasmic reticulum stress by down-regulating $\mathrm{Bcl} 2$ and perturbing the cellular redox state. Mol Cell Biol 2001, 21:1249-1259.

9. Scheuner D, Song B, McEwen E, Liu C, Laybutt R, Gillespie P, Saunders T, Bonner-Weir S, Kaufman RJ: Translational control is required for the unfolded protein response and in vivo glucose homeostasis. Mol Cell 2001, 7:1165-1176.

10. Harding HP, Zhang Y, Zeng H, Novoa I, Lu PD, Calfon M, Sadri N, Yun C, Popko B, Paules R, Stojdl DF, Bell JC, Hettmann T, Leiden JM, Ron D: An integrated stress response regulates amino acid metabolism and resistance to oxidative stress. Mol Cell 2003, 11:619-633.

11. Stohs SJ, Bagchi D: Oxidative mechanisms in the toxicity of metal ions Free Radic Biol Med 1995, 18:321-336.

12. Yokouchi M, Hiramatsu N, Hayakawa K, Okamura M, Du S, Kasai A, Takano Y, Shitamura A, Shimada T, Yao J, Kitamura M: Involvement of selective reactive oxygen species upstream of proapoptotic branches of unfolded protein response. J Biol Chem 2008, 283:4252-4260.

13. Svegliati S, Cancello R, Sambo P, Luchetti M, Paroncini P, Orlandini G, Discepoli G, Paterno R, Santillo M, Cuozzo C, Cassano S, Avvedimento EV, Gabrielli A: Plateletderived growth factor and reactive oxygen species (ROS) regulate Ras protein levels in primary human fibroblasts via ERK1/2. Amplification of ROS and Ras in systemic sclerosis fibroblasts. J Biol Chem 2005, 280:36474-36482.

14. Gobe G, Crane D: Mitochondria, reactive oxygen species and cadmium toxicity in the kidney. Toxicol Lett 2010, 198:49-55.

15. Berridge MJ, Bootman MD, Lipp P: Calcium-a life and death signal. Nature 1998, 395:645-648.

16. Wang S-H, Shih Y-L, Lee C-C, Chen W-L, Lin C-J, Lin Y-S, Wu K-H, Shih C-M: The role of endoplasmic reticulum in cadmium-induced mesangial cell apoptosis. Chem Biol Interact 2009, 181:45-51.

17. Kitamura M, Hiramatsu N: The oxidative stress: endoplasmic reticulum stress axis in cadmium toxicity. Biometals 2010, 23:941-950.

18. Lovat PE, Oliverio S, Corazzari M, Rodolfo C, Ranalli M, Goranov B, Melino G, Redfern CPF, Piacentini M: Bak: a downstream mediator of fenretinideinduced apoptosis of SH-SY5Y neuroblastoma cells. Cancer Res 2003, 63:7310-7313.

19. Korsmeyer SJ, Wei MC, Saito M, Weiler S, Oh KJ, Schlesinger PH: Pro-apoptotic cascade activates BID, which oligomerizes BAK or BAX into pores that result in the release of cytochrome c. Cell Death Differ 2000, 7:1166-1173.

20. Moriya S, Miyazawa K, Kawaguchi T, Che X-F, Tomoda A: Involvement of endoplasmic reticulum stress-mediated CHOP (GADD153) induction in the cytotoxicity of 2-aminophenoxazine-3-one in cancer cells. Int J Oncol 2011, 39:981-988.

21. Meares GP, Mines MA, Beurel E, Eom T-Y, Song L, Zmijewska AA, Jope RS: Glycogen synthase kinase-3 regulates endoplasmic reticulum (ER) stressinduced CHOP expression in neuronal cells. Exp Cell Res 2011, 317:1621-1628.

22. Rosati E, Sabatini R, Rampino G, De Falco F, Di lanni M, Falzetti F, Fettucciari K, Bartoli A, Screpanti I, Marconi P: Novel targets for endoplasmic reticulum stress-induced apoptosis in B-CLL. Blood 2010, 116:2713-2723.

23. Bork U, Lee W-K, Kuchler A, Dittmar T, Thévenod F: Cadmium-induced DNA damage triggers $\mathrm{G}(2) / \mathrm{M}$ arrest via chk1/2 and cdc2 in p53-deficient kidney proximal tubule cells. Am J Physiol Renal Physiol 2010, 298:F255-265

24. Chen L, Liu L, Huang S: Cadmium activates the mitogen-activated protein kinase (MAPK) pathway via induction of reactive oxygen species and inhibition of protein phosphatases 2A and 5. Free Radic Biol Med 2008, 45:1035-1044.

25. Yamazaki T, Ohmi A, Kurumaya H, Kato K, Abe T, Yamamoto H, Nakanishi N, Okuyama R, Umemura M, Kaise T, Watanabe R, Okawa Y, Takahashi S, Takahashi Y: Regulation of the human CHOP gene promoter by the stress response transcription factor ATF5 via the AARE1 site in human hepatoma HepG2 cells. Life Sci 2010, 87:294-301.
26. Haynes CM, Titus EA, Cooper AA: Degradation of misfolded proteins prevents ER-derived oxidative stress and cell death. Mol Cell 2004, 15:767-776

27. Zinszner $H$, Kuroda M, Wang X, Batchvarova N, Lightfoot RT, Remotti $H$, Stevens $J$, Ron D: CHOP is implicated in programmed cell death in response to impaired function of the endoplasmic reticulum. Genes Dev 1998, 12:982-995.

28. Ramji DP, Foka P: CCAAT/enhancer-binding proteins: structure, function and regulation. Biochem J 2002, 365:561-575.

doi:10.1186/1471-2121-14-4

Cite this article as: Kim et al:: Cadmium induces neuronal cell death through reactive oxygen species activated by GADD153. BMC Cell Biology 2013 14:4

\section{Submit your next manuscript to BioMed Central and take full advantage of:}

- Convenient online submission

- Thorough peer review

- No space constraints or color figure charges

- Immediate publication on acceptance

- Inclusion in PubMed, CAS, Scopus and Google Scholar

- Research which is freely available for redistribution

Submit your manuscript at www.biomedcentral.com/submit
C) Biomed Central 